\title{
Low-Temperature $\mathrm{H}_{2} \mathrm{~S}$ Sensors Based on Si-Coated $\mathrm{SnO}_{2}$ Nanowires
}

\author{
Myung Sik Choi ${ }^{1}$, Ali Mirzaei ${ }^{2,3}$, Jae Hoon Bang ${ }^{1}$, Han Gil Na ${ }^{1}$, Changhyun Jin $^{1,2}$, Wansik Oum ${ }^{1}$, \\ Seungmin Han', Sang Sub Kim, ${ }^{4, *}$ and Hyoun Woo Kim ${ }^{1,2, *}$ \\ ${ }^{1}$ Division of Materials Science and Engineering, Hanyang University, Seoul 04763, Republic of Korea \\ ${ }^{2}$ The Research Institute of Industrial Science, Hanyang University, Seoul 04763, Republic of Korea \\ ${ }^{3}$ Department of Materials Science and Engineering, Shiraz University of Technology, Shiraz, Iran \\ ${ }^{4}$ Department of Materials Science and Engineering, Inha University, Incheon 22212, Republic of Korea
}

\begin{abstract}
To attain high life standards, it is important to develop high-performance non-toxic gas sensors for public safety, environmental pollutant control, industrial processes, etc. Because reports on single element semiconductor-coated semiconducting metal oxides for sensing applications are rare, we synthesized $\mathrm{SnO}_{2}$ nanowires and coated them with a $5 \mathrm{~nm}$-thick or $10 \mathrm{~nm}$-thick $\mathrm{Si}$ layer for $\mathrm{H}_{2} \mathrm{~S}$ gas sensing studies. $\mathrm{SnO}_{2}$ nanowires were successfully synthesized using a highly pure metallic Sn powder at high temperature in a tube furnace by the vapor-liquid-solid method and $\mathrm{Si}$ was deposited on the nanowires by the sputtering technique. The desired morphology and composition of the synthesized nanowires were confirmed by scanning electron microscopy, transmission electron microscopy, X-ray diffraction, and energy-dispersive X-ray spectroscopy. Moreover, the gas sensing characteristics of pristine and $\mathrm{Si}$-coated $\mathrm{SnO}_{2}$ nanowires toward $\mathrm{H}_{2} \mathrm{~S}$, $\mathrm{CO}, \mathrm{H}_{2}, \mathrm{C}_{6} \mathrm{H}_{6}, \mathrm{C}_{2} \mathrm{H}_{5} \mathrm{OH}$ and $\mathrm{C}_{6} \mathrm{H}_{7}$ gases were investigated. The sensing results revealed a good response to $\mathrm{H}_{2} \mathrm{~S}$ at the optimum operational temperature of $100{ }^{\circ} \mathrm{C}$. Notably, Si-coated $\mathrm{SnO}_{2}$ nanowire sensors showed a better response to $\mathrm{H}_{2} \mathrm{~S}$ than pristine $\mathrm{SnO}_{2}$ nanowires. The mechanism of $\mathrm{H}_{2} \mathrm{~S}$ sensing is discussed in detail here. This study shows that the $\mathrm{Si}$ coating on the $\mathrm{SnO}_{2}$ nanowire enhances its sensing performance and decreases the sensing temperature required for $\mathrm{H}_{2} \mathrm{~S}$ gas detection.
\end{abstract}

(Received May 3, 2019; Accepted September 7, 2019)

Keywords: $\mathrm{SnO}_{2}$, nanowires, $\mathrm{Si}$, coating, $\mathrm{H}_{2} \mathrm{~S}$, gas sensor, semiconductor

\section{INTRODUCTION}

The considerable demand for materials with enhanced properties that can satisfy the requirements of modern technology in the $21^{\text {st }}$ century has resulted in the development of one-dimensional nanomaterials such as nanowires [1], nanorods [2], and nanofibers [3]. Their high aspect ratios as well as good electrical, mechanical, chemical, and thermal properties [4] have led to their application in batteries [5], photocatalysts [6], fuel cells [7], gas sensors [8], etc. Gas adsorption strongly depends on the number of available adsorption sites; because nanowires provide very

- Myung Sik Choi: 박사과정, Ali Mirzaei·Changhyun Jin·Sang Sub Kim·Hyoun Woo Kim: 교수, Jae Hoon Bang: 석박사통합과정, Wansik Oum·Seungmin Han:석사과정 *Corresponding Author: Sang Sub Kim [Tel: +82-82-32-960-7546, E-mail: sangsub@inha.ac.kr] *Corresponding Author: Hyoun Woo Kim [Tel: +82-2-2220-0382, E-mail: hyounwoo@hanyang.ac.kr] Copyright (c) The Korean Institute of Metals and Materials high surface areas for gas adsorption, they have found particular attention in the field of gas sensors. Notably, nanowire-based gas sensors exhibit high sensitivity, short response times, and high stability; in addition, they are lightweight and can operate at lower temperatures than sensors fabricated from their bulk counterparts [9]. Therefore, several nanowire-based gas sensors have been developed [10-13]. Stannic oxide $\left(\mathrm{SnO}_{2}\right)$ is one of the most important n-type semiconducting $\left(\mathrm{E}_{\mathrm{g}} \sim 3.6 \mathrm{eV}\right)$ metal oxides [14] and has been used in gas sensors [15-17]. However, its working temperature is often high and it generally shows poor selectivity [18,19]. To address these issues, the morphology of $\mathrm{SnO}_{2}$ nanowires has been altered [20] and n-p junctions based on composites of $\mathrm{SnO}_{2}$ and other p-type metal oxides [21] have been fabricated. $\mathrm{SnO}_{2}-\mathrm{Si}$ heterojunction nanowires are promising materials for gas sensing applications. Si-based gas sensors [11] have currently received significant interest for gas sensing because of their 
low working temperatures [10] and compatibility with silicon technology [22]; however, their response is low [23] and their performance needs to be improved. In the case of a $\mathrm{SnO}_{2}-\mathrm{Si}$ sensor, $\mathrm{SnO}_{2}$ provides enhanced sensing characteristics while $\mathrm{Si}$ decreases the working temperature, making the sensor highly compatible with silicon technology. Some researchers have investigated composites of $\mathrm{Si}$ with other metal oxides for sensing applications. For example, Zhang et al. [24] fabricated an $\mathrm{NO}_{2}$ gas sensor based on $\mathrm{Si} / \mathrm{WO}_{3}$ nanowires that functioned at room temperature. Liu et al. [25] reported $\mathrm{NO}_{2}$ gas sensing with $\mathrm{CuO} /$ p-porous silicon heterojunctions at room temperature. However, to the best of our knowledge, $\mathrm{H}_{2} \mathrm{~S}$ sensing properties of $\mathrm{Si}$-coated $\mathrm{SnO}_{2}$ nanowires have not been investigated. In this work, Si-coated $\mathrm{SnO}_{2}$ nanowires were synthesized by thermal evaporation, and then, $\mathrm{Si}$ was sputtered on the nanowires. The fabricated Si-coated $\mathrm{SnO}_{2}$ nanowires demonstrated an enhanced response to $\mathrm{H}_{2} \mathrm{~S}$ compared to pristine $\mathrm{SnO}_{2}$ nanowires. The sensing mechanisms are explained in detail in this report.

\section{EXPERIMENTAL PROCEDURE}

\subsection{Synthesis}

$\mathrm{SnO}_{2}$ nanowires were produced in a tube furnace. For the synthesis, metallic Sn nanopowder with a purity of $99.9 \%$ was used as the raw material. Typically, a 3 nm-thick Au layer was coated on a Si substrate as catalyst; the Au-coated substrate was heated at $900{ }^{\circ} \mathrm{C}$ for $1 \mathrm{~h}$, and then, exposed to a mixture of $\mathrm{Ar}(97 \%)$ and $\mathrm{O}_{2}(3 \%)$ gases at a constant flow rate and total pressure of 2 Torr. The details of the $\mathrm{SnO}_{2}$ nanowire synthesis have been reported in our previous publications [26,27].

$\mathrm{Si}$ was coated on the as-grown $\mathrm{SnO}_{2}$ nanowires by radio frequency (RF) sputtering with a $\mathrm{Si}$ target at room temperature. The optimal pressure for the $\mathrm{Si}$ shell layer deposition was 10 mTorr in Ar ambient and the RF power during the deposition was set to $50 \mathrm{~W}$. The sputtering time was varied from $2 \mathrm{~min}$ to $4 \mathrm{~min}$ to obtain $\mathrm{Si}$ shells with thicknesses of $5 \mathrm{~nm}$ and $10 \mathrm{~nm}$, respectively.

\subsection{Material Characterization}

The crystallinity and phase purity of the prepared samples were investigated by X-ray diffraction (XRD) using a Philips
X'Pert diffractometer with the $\mathrm{Cu} \mathrm{K}_{\alpha 1}$ radiation $(\lambda=1.5404$ $\AA$ ). The morphology was investigated by scanning electron microscopy (SEM, Hitachi S-4200) and transmission electron microscopy (TEM, Philips CM 200). Energy-dispersive Xray spectroscopy (EDS) was performed to study the chemical composition of the synthesized products. The work function of $\mathrm{SnO}_{2}$ nanowires was determined from the ultraviolet photoelectron spectroscopy (UPS) profiles recorded using an HeI $(21.2 \mathrm{eV})$ ultraviolet source.

\subsection{Sensor Fabrication and Gas Sensing Tests}

Details of the gas sensing tests can be found elsewhere [2830]. A bi-layered electrode comprising a Au layer (300 nmthick) and a Ti layer (50 nm-thick) was sputter-deposited on each sample. The gas flow was controlled by changing the mixing ratio of dry air to the target gas using mass flow controllers under a total stream of $500 \mathrm{sccm}$. All measurements were carried out in a special gas chamber and the sensor resistance data were obtained using a source meter. The sensor response (R) is defined as $R=R_{a} / R_{g}$, where $R_{a}$ and $R_{g}$ are the resistances of the sensor in air and in the presence of the target gas, respectively. The response and recovery times were calculated as the time to reach $90 \%$ of the final signal after exposure and stoppage of the target gas, respectively.

\section{RESULTS AND DISCUSSION}

\subsection{Morphological and Structural Studies}

The morphology of the synthesized nanowires was studied by SEM and the micrographs are presented in Fig. 1 (a)-(f). Fig. 1(a) reveals bare, curvy, and continuous $\mathrm{SnO}_{2}$ nanowires with lengths in the order of several micrometers and diameters of $\sim 100 \mathrm{~nm}$. Figure 1(b) is a high-magnification SEM image showing the smooth morphology of the synthesized bare $\mathrm{SnO}_{2}$ nanowires. Figure 1(c) shows Sicoated $\mathrm{SnO}_{2}$ nanowires with a shell thickness of $5 \mathrm{~nm}$ and the high-magnification SEM image in Fig. 1(d) shows the relatively smooth morphology of the coated nanowires. Figure 1(e) and (f) show the SEM images of Si-coated (10 nm) $\mathrm{SnO}_{2}$ nanowires. Coating with a $10 \mathrm{~nm} \mathrm{Si} \mathrm{shell} \mathrm{resulted}$ in a relatively rough morphology.

To determine the crystal structure of the synthesized 

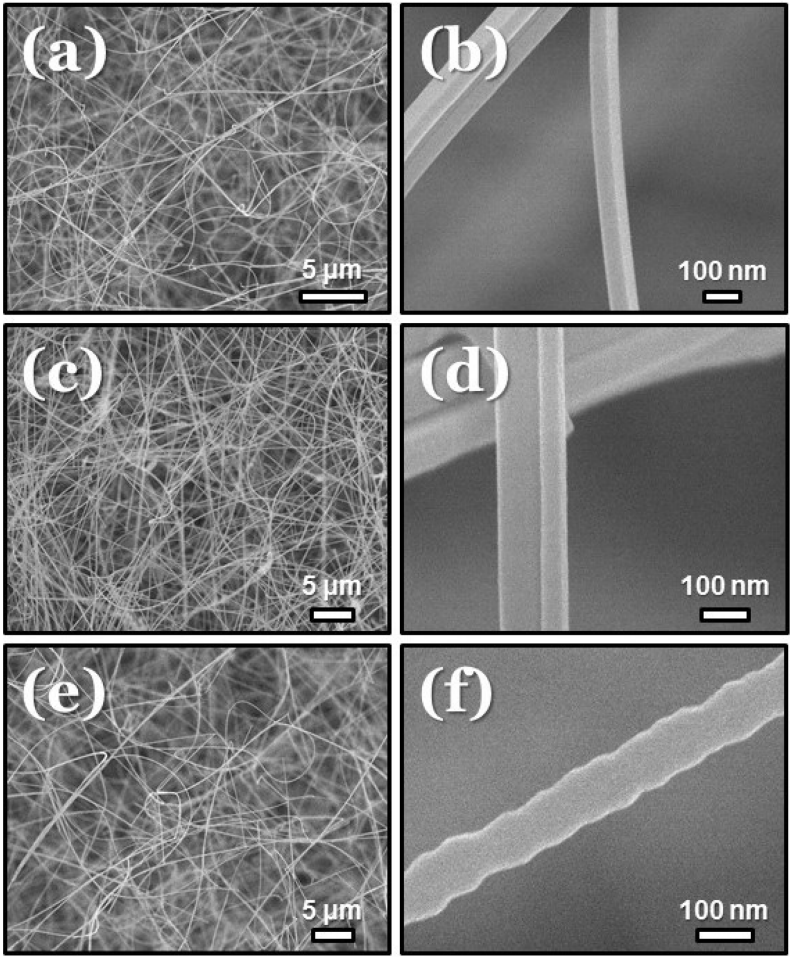

Fig. 1. SEM images of (a) and (b) bare $\mathrm{SnO}_{2}$ nanowires, (c) and (d) $\mathrm{SnO}_{2}$ nanowires with 5 nm-thick $\mathrm{Si}$ shells, and (e) and (f) $\mathrm{SnO}_{2}$ nanowires with $10 \mathrm{~nm}$-thick $\mathrm{Si}$ shells.

nanowires, XRD patterns of bare and $\mathrm{Si}$-coated $\mathrm{SnO}_{2}$ nanowires were recorded and are shown in Fig. 2(a)-(c).

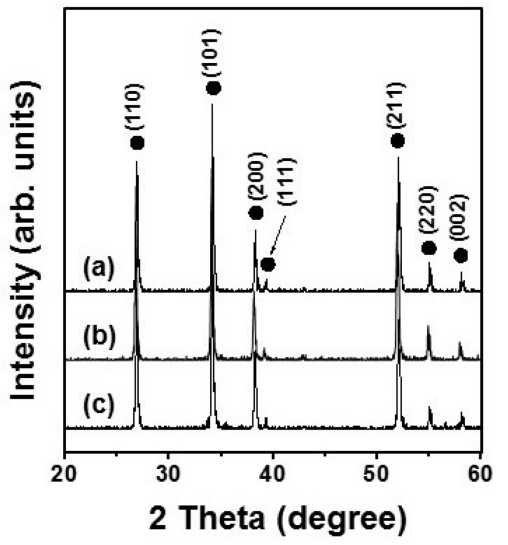

Fig. 2. XRD patterns of (a) bare $\mathrm{SnO}_{2}$ nanowires and $\mathrm{SnO}_{2}$ nanowires with $\mathrm{Si}$ shell thicknesses of (b) $5 \mathrm{~nm}$ and (c) $10 \mathrm{~nm}$.

Common peaks for all materials were observed at $2 \theta=26.61$, $33.92,37.99,39.02,51.83,54.81$, and $57.91^{\circ}$, corresponding to the (110), (101), (200), (111), (211), (220), and (002) planes of $\mathrm{SnO}_{2}$, respectively. Si peaks at $2 \theta=26.87$ (200), 33.07 (211), 38.37 (220), 51.53 (321), 55.38 (400), and $59.06^{\circ}$ (411), originating from the $\mathrm{Si}$ shell, overlapped with the $\mathrm{SnO}_{2}$ peaks. In addition, the microstructures of bare and Si-coated $\mathrm{SnO}_{2}$ nanowires were studied by TEM and the micrographs are presented in Fig. 3. TEM images of $\mathrm{SnO}_{2}$ nanowires with shell thicknesses of $5 \mathrm{~nm}$ and $10 \mathrm{~nm}$ are shown in Fig. 3(a) and 3(d), respectively. As observed, the
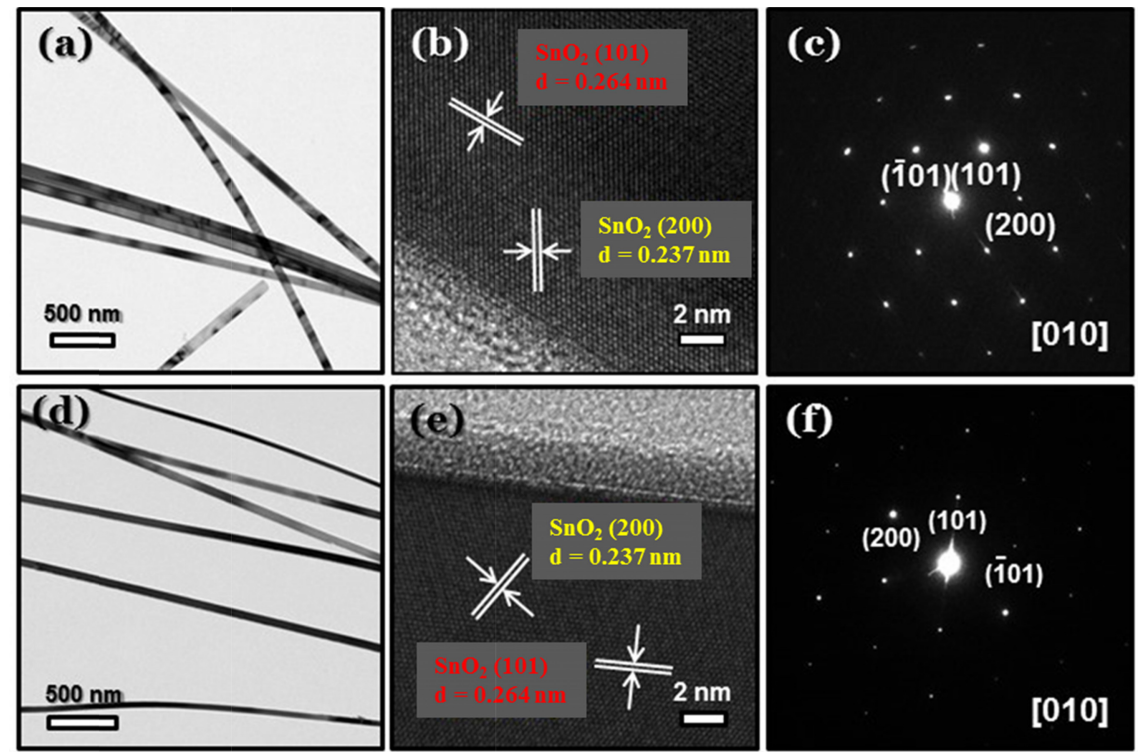

Fig. 3. (a) TEM and (b) HRTEM images and (c) SAED pattern of $\mathrm{SnO}_{2}$ nanowires with a shell thickness of $5 \mathrm{~nm}$. (d) TEM and (e) HRTEM images and (f) SAED pattern of $\mathrm{SnO}_{2}$ nanowires with a shell thickness of $10 \mathrm{~nm}$. 

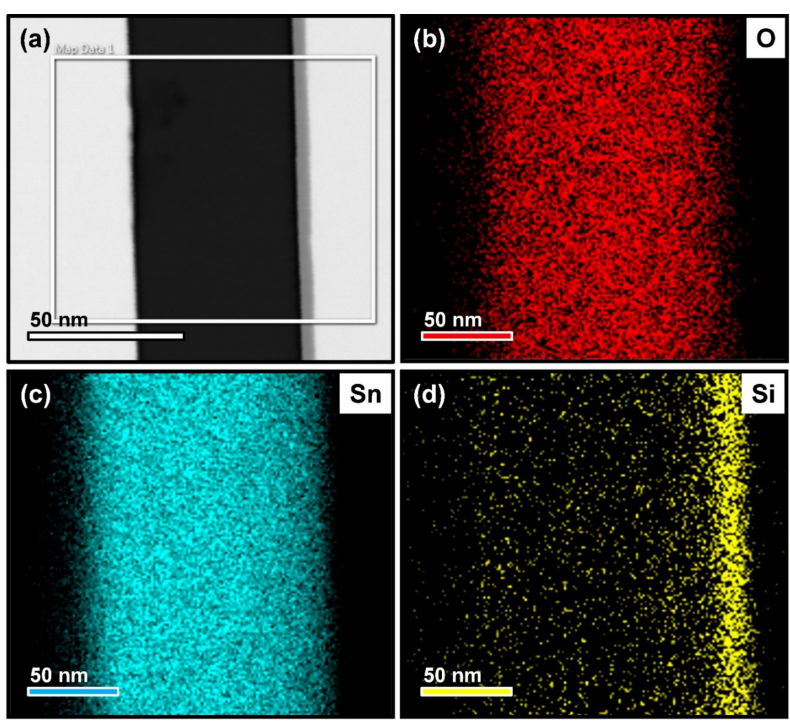

Fig. 4. EDS elemental mapping images showing the presence of $\mathrm{Si}$, $\mathrm{Sn}$, and $\mathrm{O}$.

nanowires were long and separate from one other, suggesting that they can provide high surface areas for gas adsorption. The diameters of the nanowires were about $100 \mathrm{~nm}$, in accordance with the SEM results. The high-resolution TEM (HRTEM) images of $\mathrm{SnO}_{2}$ nanowires with shell thicknesses of $5 \mathrm{~nm}$ and $10 \mathrm{~nm}$ are shown in Fig. 3(b) and 3(e), respectively. In both cases, lattice fringes with spacings of $0.264 \mathrm{~nm}$ and $0.237 \mathrm{~nm}$, corresponding to the (101) and (200) planes of $\mathrm{SnO}_{2}$, respectively, were observed. This result further confirmed the crystalline nature of the $\mathrm{SnO}_{2}$ nanowires. The corresponding selected area diffraction (SAED) patterns showing distinct diffraction spots are presented in Fig. 3(c) and 3(f) which confirms the single crystalline nature of the synthesized $\mathrm{SnO}_{2}$ nanowires. The EDS elemental mapping images revealing the presence $\mathrm{Si}, \mathrm{Sn}$, and $\mathrm{O}$ in the synthesized nanowires are shown in Fig. 4. It is noteworthy that a thin $\mathrm{Si}$ layer covered the $\mathrm{SnO}_{2}$ nanowires.

\subsection{Gas Sensing Studies}

From a series of preliminary tests, we determined that the optimal working temperature of the sensors was $100{ }^{\circ} \mathrm{C}$; therefore, all gas sensing measurements were performed at $100{ }^{\circ} \mathrm{C}$. Fig. 5 shows the $\mathrm{H}_{2} \mathrm{~S}$ sensing properties of bare and Si-coated $\mathrm{SnO}_{2}$ nanowires. The dynamic response plots of bare $\mathrm{SnO}_{2}$ nanowires for 10, 20, and $50 \mathrm{ppm}$ of $\mathrm{H}_{2} \mathrm{~S}$ gas are shown in Fig. 5(a). Upon exposure to $\mathrm{H}_{2} \mathrm{~S}$ gas, the resistance
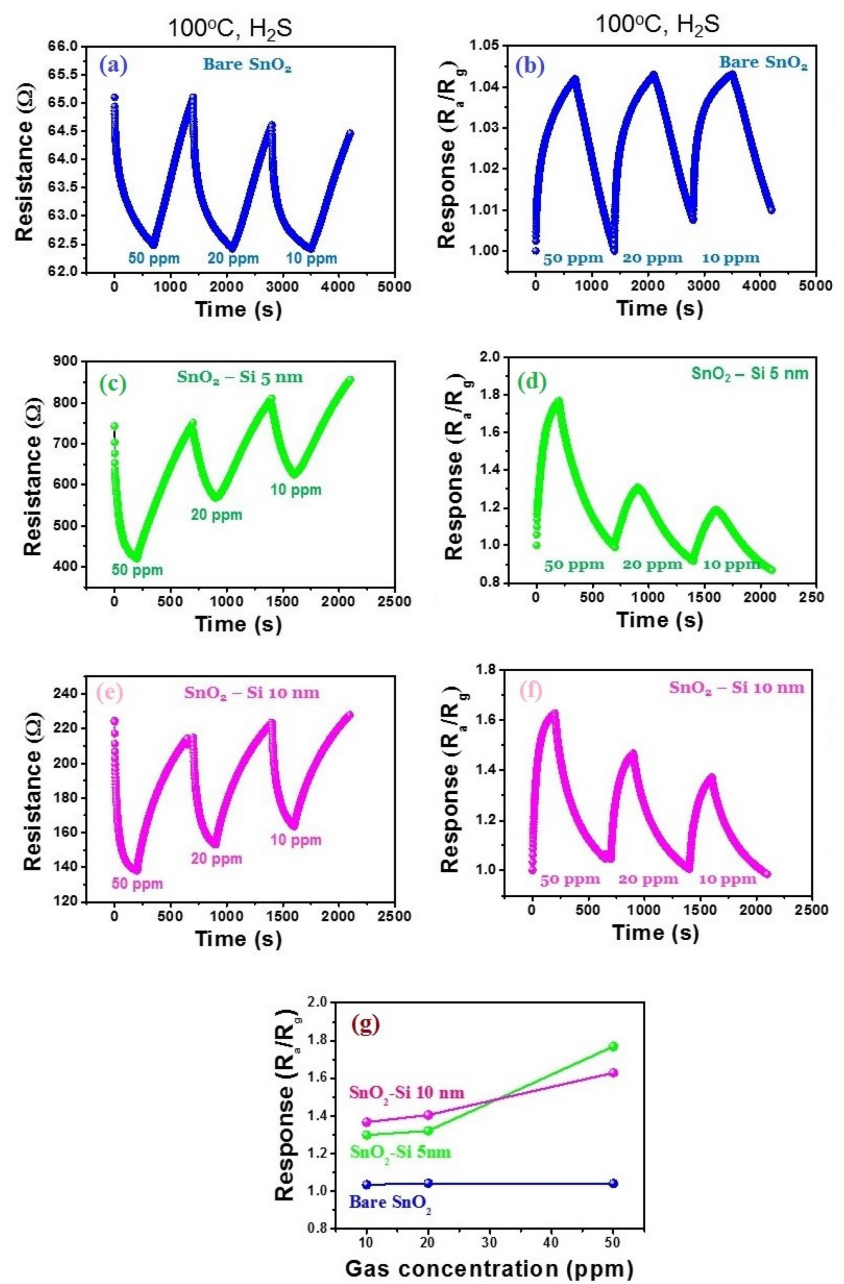

Fig. 5. Dynamic responses of (a) bare $\mathrm{SnO}_{2}$ nanowires and $\mathrm{SnO}_{2}$ nanowires with $\mathrm{Si}$ shell thicknesses of (c) $5 \mathrm{~nm}$ and (e) $10 \mathrm{~nm}$ toward 10, 20, and $50 \mathrm{ppm}$ of $\mathrm{H}_{2} \mathrm{~S}$ gas at $100{ }^{\circ} \mathrm{C}$. Response of (b) bare $\mathrm{SnO}_{2}$ nanowires and $\mathrm{SnO}_{2}$ nanowires with shell thicknesses of (d) $5 \mathrm{~nm}$ and (f) $\mathrm{SnO}_{2} 10 \mathrm{~nm}$ toward 10, 20, and $50 \mathrm{ppm}$ of $\mathrm{H}_{2} \mathrm{~S}$ gas at $100{ }^{\circ} \mathrm{C} .(\mathrm{g})$ Corresponding calibration curves.

of the sensor decreased, reflecting its n-type behavior. Furthermore, the response was reversible, because after stopping the injection of $\mathrm{H}_{2} \mathrm{~S}$ and air, the resistance returned to its initial value. The response $\left(\mathrm{R}_{\mathrm{a}} / \mathrm{R}_{\mathrm{g}}\right)$ versus time plots are presented in Fig. 5(b). The responses of the bare $\mathrm{SnO}_{2}$

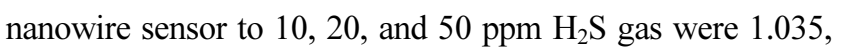
1.043 , and 1.043, respectively, indicating that the response was almost identical for different concentrations of $\mathrm{H}_{2} \mathrm{~S}$ gas. This was likely due to the limited surface area of the bare $\mathrm{SnO}_{2}$ nanowire. The dynamic response plots of $5 \mathrm{~nm}$-thick and $10 \mathrm{~nm}$-thick $\mathrm{Si}$ shell-coated $\mathrm{SnO}_{2}$ nanowires for different concentrations of $\mathrm{H}_{2} \mathrm{~S}$ are shown in Fig. 5(c) and 5(e), 
respectively. Both sensors showed n-type behaviors and reversible responses. Fig. 5(d) and 5(f) show plots of response as a function of time for $\mathrm{SnO}_{2}$ nanowires coated with $5 \mathrm{~nm}$ - or $10 \mathrm{~nm}$-thick $\mathrm{Si}$ shells. The responses of $\mathrm{SnO}_{2}$ nanowires with $5 \mathrm{~nm}$ Si shells to 10,20 , and $50 \mathrm{ppm}$ of $\mathrm{H}_{2} \mathrm{~S}$ gas were 1.299, 1.321, and 1.769, respectively, while those of $\mathrm{SnO}_{2}$ nanowires with 10 nm-thick $\mathrm{Si}$ shells were 1.367, 1.405 , and 1.629, respectively. The calibration curves of all sensors are shown in Fig. 5(g). Clearly, the response of bare $\mathrm{SnO}_{2}$ nanowires was far lower than that of Si-coated $\mathrm{SnO}_{2}$ nanowires. This demonstrated that $\mathrm{Si}$ enhanced the sensing performance of the $\mathrm{SnO}_{2}$ nanowire. Furthermore, the nanowires with $5 \mathrm{~nm}$-thick $\mathrm{Si}$ shells showed a higher response to $50 \mathrm{ppm}$ of $\mathrm{H}_{2} \mathrm{~S}$ than those with $10 \mathrm{~nm}$-thick shells; on the other hand, to $10 \mathrm{ppm}$ and $20 \mathrm{ppm}$ of $\mathrm{H}_{2} \mathrm{~S}$, the response of nanowires with $5 \mathrm{~nm}$-thick Si shells was higher.

Selectivity for a target gas is highly important for real
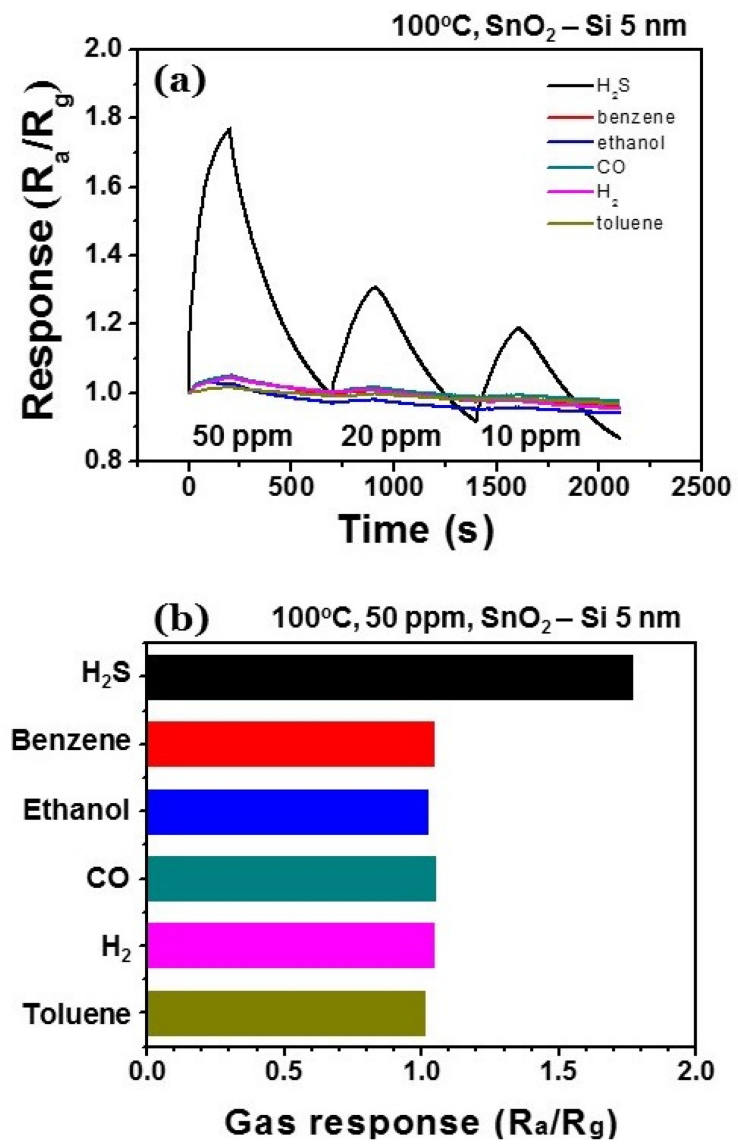

Fig. 6. (a) Transient response of $\mathrm{SnO}_{2}-\mathrm{Si}(10 \mathrm{~nm})$ sensor toward different gases at $100{ }^{\circ} \mathrm{C}$. (b) Selectivity histogram of $\mathrm{SnO}_{2}$-Si $(5$ $\mathrm{nm})$ sensor to $50 \mathrm{ppm}$ of gases tested at $100{ }^{\circ} \mathrm{C}$. applications because a lack of selectivity can lead to false alarms, limiting the practical application of a sensor. To study the selectivity of $5 \mathrm{~nm}$-thick $\mathrm{Si}$ shell-coated $\mathrm{SnO}_{2}$ nanowires, they were exposed to $50 \mathrm{ppm}$ of benzene, ethanol, $\mathrm{CO}, \mathrm{H}_{2}$, and toluene gases at $100{ }^{\circ} \mathrm{C}$. Fig. 6(a) shows the variations in responses to these gases with time; the corresponding selectivity histogram of the sensor is presented in Fig. 6(b). The sensor responses to the gases were 1.051, 1.028, 1.052, 1.047 , and 1.016, respectively, indicating that these sensors were largely insensitive to interfering gases.

\subsection{Gas Sensing Mechanism}

Several factors can influence the sensing behavior of $\mathrm{Si}$ shelled $\mathrm{SnO}_{2}$ nanowires. When considering the changes in the resistance of a $\mathrm{SnO}_{2}-\mathrm{Si}$ core-shell nanowire upon exposure to $\mathrm{H}_{2} \mathrm{~S}$ gas, the change in the resistance of the $\mathrm{SnO}_{2}$ nanowire core $\left(\mathrm{R}_{1}\right)$ and the change in the resistance of the $\mathrm{Si}$ shell $\left(\mathrm{R}_{2}\right)$ should be taken into account [28]. Almost every gas adsorbs onto the surface of a metal oxide [31]. The most prominent reactive gas in normal ambient air is molecular oxygen. Depending on the sensor operation temperature, oxygen adsorbs in various forms onto the metal oxide surface. Exposure of a pristine $\mathrm{SnO}_{2}$ nanowire sensor to air results in the adsorption of oxygen molecules onto the surface of the nanowire. Because of the high electron affinity of oxygen, the adsorbed oxygen molecules trap electrons from the conduction band of $\mathrm{SnO}_{2}$, forming ionized oxygen species such as $\mathrm{O}_{2}^{-}, \mathrm{O}^{-}$, and $\mathrm{O}^{2-}$ [2]:

$$
\begin{aligned}
& \mathrm{O}_{2(\text { gas })} \rightarrow \mathrm{O}_{2(\text { ads })} \\
& \mathrm{O}_{2(\text { ads })}+\overline{\mathrm{e}}=\mathrm{O}_{2(\mathrm{ads})}^{-} \\
& \mathrm{O}_{2(\mathrm{ads})}^{-}+\overline{\mathrm{e}}=2 \mathrm{O}_{(\mathrm{ads})}^{-} \\
& \mathrm{O}_{(\mathrm{ads})}^{-}+\overline{\mathrm{e}}=\mathrm{O}_{(\mathrm{ads})}^{2-}
\end{aligned}
$$

Consequently, the concentration of electrons on the surface decreases, and accordingly, the resistance of the $\mathrm{SnO}_{2}$ nanowires increases. When a pristine $\mathrm{SnO}_{2}$ nanowire gas sensor is exposed to $\mathrm{H}_{2} \mathrm{~S}, \mathrm{H}_{2} \mathrm{~S}$ molecules chemisorb on the surface of the $\mathrm{SnO}_{2}$ nanowire, and electrons are released by a subsequent reaction with oxygen ions, resulting in $\mathrm{H}_{2} \mathrm{O}$ and $\mathrm{SO}_{2}$ gases [32]:

$$
\mathrm{H}_{2} \mathrm{~S}_{(\mathrm{ads})}=3 \mathrm{O}_{(\mathrm{ads})}^{-}=\mathrm{SO}_{2(\mathrm{~g})}+\mathrm{H}_{2} \mathrm{O}+3 \mathrm{e}^{-}
$$


The released electrons decrease the resistance of the gas sensor, resulting in a response. Because the core $\mathrm{SnO}_{2}$ nanowires were single crystalline, the effects of grain boundaries were excluded. After $\mathrm{Si}$ was coated on the $\mathrm{SnO}_{2}$ nanowires, an increase in response was observed. As observed in Fig. 5(g), the response of the Si-shelled nanowires was superior to that of bare nanowires, regardless of the gas concentration or shell thickness. The $\mathrm{H}_{2} \mathrm{~S}$ gas sensing mechanism for the Si-coated $\mathrm{SnO}_{2}$ nanowire sensor can be explained on the basis of several factors. The TEM results revealed that the $\mathrm{Si}$ shell layer did not completely cover the core nanowire, wherein a part of the core was exposed along the entire length of the nanowire. More importantly, the sensor exhibited an n-type behavior, illustrating the dominant role of the $\mathrm{SnO}_{2}$ nanowire core in sensing.

Similar to that for the $\mathrm{SnO}_{2}$ nanowires, adsorption of $\mathrm{H}_{2} \mathrm{~S}$ gas likely changed the resistance of the Si shell layer. When $\mathrm{SnO}_{2}$ nanowires with $\mathrm{Si}$ shell layers were exposed to $\mathrm{H}_{2} \mathrm{~S}$, electrons were released, as shown in Eq. (7). Because the Si shell layer had a p-type semiconducting property, the adsorption of $\mathrm{H}_{2} \mathrm{~S}$ gas resulted in the donation of electrons or extraction of holes, generating a hole depletion region. Thus, when $\mathrm{H}_{2} \mathrm{~S}$ gas was introduced, the resistance of the $\mathrm{Si}$ shell layer increased. Furthermore, because the Si shell layer was polycrystalline, modulation of resistance might occur along grain boundaries.

An important difference between the pristine and Si-coated $\mathrm{SnO}_{2}$ nanowire sensors is the existence of $\mathrm{Si}-\mathrm{SnO}_{2} \mathrm{p}-\mathrm{n}$ junctions. Notably, $\mathrm{SnO}_{2} / \mathrm{Si}$ heterointerfaces affect the sensing behavior. In particular, the conductivity, accumulation of electrons, and size of the electron depletion region prior to $\mathrm{H}_{2} \mathrm{~S}$ introduction will determine the sensor response. The work function of $\mathrm{SnO}_{2}$ is reported to be in the range of 4.0-5.7 eV [33-47]. In this study, the work function of $\mathrm{SnO}_{2}$ nanowires was measured to be $4.8 \mathrm{eV}$. From the UPS profile of $\mathrm{SnO}_{2}$, the cut-off value was determined to be $16.5 \mathrm{eV}$ (Fig. 7). The work function was calculated by subtracting the cut-off value from the reference value of $21.1 \mathrm{eV}$. To correct the broadening due to the analyzer, $0.1 \mathrm{eV}$ was added to each work function value. Accordingly, the work function of the $\mathrm{SnO}_{2}$ nanowire was calculated to be $4.8 \mathrm{eV}(=21.2 \mathrm{eV}-16.5 \mathrm{eV}+0.1 \mathrm{eV})$. Previous studies have reported that the work function of $\mathrm{Si}$ falls within the range of 4.1-5.0 eV [48-60]. In particular, the
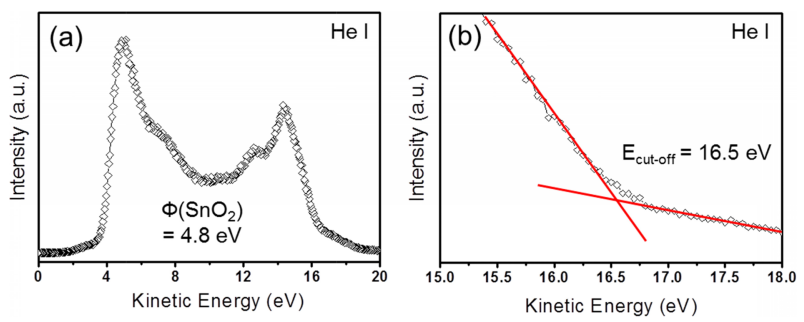

Fig. 7. (a) UPS profile of $\mathrm{SnO}_{2}$ nanowires. (b) Calculation of cut-off value.

work function of p-type $\mathrm{Si}$ is 4.7-5.0 eV [59]. There are two possible explanations for the enhanced response observed in the presence of the Si shell, both of which depend on the relative magnitudes of the work functions.

One possibility is that the Fermi level $\left(\mathrm{E}_{\mathrm{F}}\right)$ of $\mathrm{p}-\mathrm{Si}$ is higher than that of $\mathrm{SnO}_{2}$. In this case, the work function of $\mathrm{SnO}_{2}$ will be larger than that of $\mathrm{p}-\mathrm{Si}$. Therefore, electrons from $\mathrm{p}-\mathrm{Si}$ will flow to $\mathrm{SnO}_{2}$ to balance the Fermi levels. At the same time, holes from $\mathrm{SnO}_{2}$ will flow to p-Si. Consequently, electron and hole accumulation layers will be generated on the $\mathrm{SnO}_{2}$ and $\mathrm{p}$ $\mathrm{Si}$ sides of the heterojunction, respectively. Subsequently, the conduction volume of the $\mathrm{SnO}_{2}$ core will increase and a corresponding change in the conduction volume due to the introduction/removal of $\mathrm{H}_{2} \mathrm{~S}$ gas will generate a lower sensor response. The other possibility is that the Fermi level $\left(\mathrm{E}_{\mathrm{F}}\right)$ of p-Si is lower than that of $\mathrm{SnO}_{2}$ (Fig. 8(a)). In this case, the work function of $\mathrm{SnO}_{2}$ will be smaller than that of $\mathrm{p}-\mathrm{Si}$. Thus, electrons from $\mathrm{SnO}_{2}$ will flow to p-Si (Fig. 8(b)). Consequently, electron and hole depletion layers will be generated on the $\mathrm{SnO}_{2}$ and $\mathrm{p}$-Si sides of the heterojunction, respectively. Subsequently, the initial conduction volume in the $\mathrm{SnO}_{2}$ core will decrease and a corresponding change in the conduction volume due to the introduction/removal of $\mathrm{H}_{2} \mathrm{~S}$ gas will generate a higher sensor response. As observed in Fig. 5(g), the addition of the $\mathrm{Si}$ shell layer enhanced the response of the bare nanowire sensor, indicating that the work function of $\mathrm{SnO}_{2}$ was smaller than that of $\mathrm{p}-\mathrm{Si}$ in this work. Moreover, the deposition of $\mathrm{Si}$ onto the $\mathrm{SnO}_{2}$ nanowires might introduce structural defects, favoring the adsorption of the target gas as well as oxygen molecules, and thereby, leading to an increase in the sensor signal [29].

A schematic diagram of the sensing mechanism for the fabricated sensors is given in Fig. 9. Notably, the TEM results showed that the shell layer was partially open, in other 
(a) Before contact
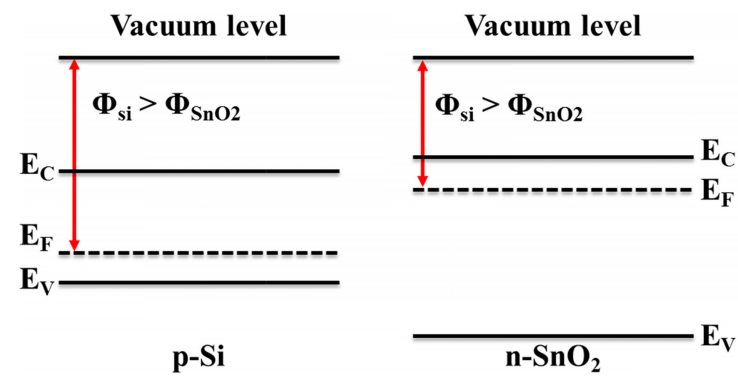

(b) After contact in air

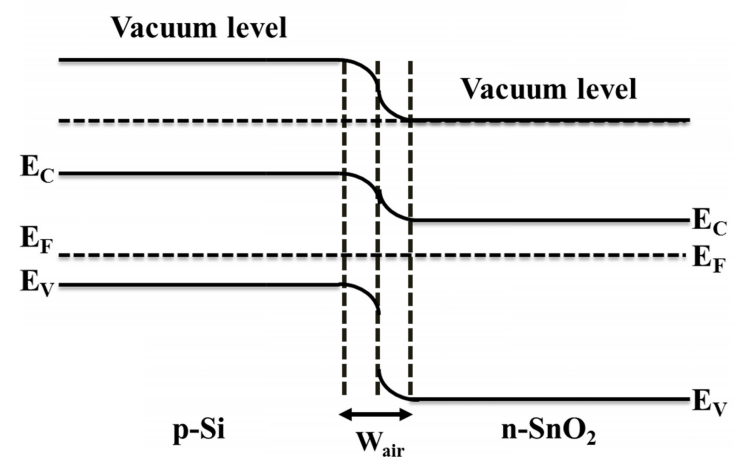

Fig. 8. (a) Band structure of $n-\mathrm{SnO}_{2}$ and $\mathrm{p}-\mathrm{Si}$ before contact and (b) after contact in air.

words, the shell layer partially covered the core $\mathrm{SnO}_{2}$ nanowire. Because the shell was preferentially deposited on one side of the core nanowire, the shell was partially open and a considerable part of the $\mathrm{SnO}_{2}$ core was exposed to air ambient. Accordingly, electron currents in the $\mathrm{n}-\mathrm{SnO}_{2}$ core and hole currents in $\mathrm{p}-\mathrm{Si}$ contributed to the sensing behavior. Because of the work function difference between $\mathrm{Si}$ and $\mathrm{SnO}_{2}$ in air and exposure of the bare surfaces to air, a hole accumulation layer, a hole depletion layer, and an electron depletion layer were formed (see Fig. 9(a)). As shown in Fig. 9(a), the hole and electron depletion layers were formed on the $\mathrm{p}-\mathrm{Si}$ and $\mathrm{n}-\mathrm{SnO}_{2}$ sides, respectively, at the interface between $\mathrm{p}$-Si and $\mathrm{n}-\mathrm{SnO}_{2}$. Upon exposure to $\mathrm{H}_{2} \mathrm{~S}$, electrons returned to the surface of the sensing layer, decreasing the width of the electron and hole depletion layers and the hole accumulation layer, as shown in Fig. 9(b).

The introduction of $\mathrm{H}_{2} \mathrm{~S}$ gas resulted in a decrease in the resistance of both bare and Si-coated $\mathrm{SnO}_{2}$ nanowire sensors. Thus, the sensors exhibited n-type behaviors. Accordingly, we surmised that the main sensing current was the electron (a) In air

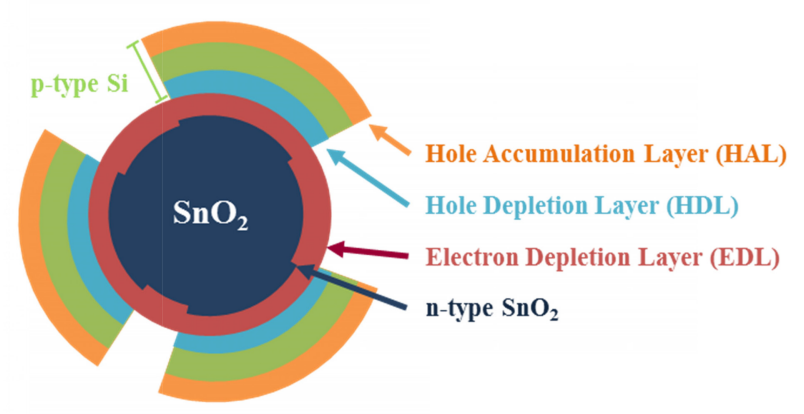

\section{(b) $\mathrm{In} \mathrm{H}_{2} \mathrm{~S}$}

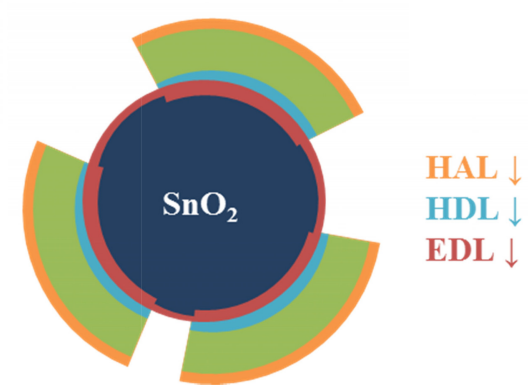

Fig. 9. Schematic illustration of variation in the conduction channel of $\mathrm{SnO}_{2}$ nanowire coated with $\mathrm{Si}$ in (a) air and (b) $\mathrm{H}_{2} \mathrm{~S}$ atmospheres. (HAL: hole accumulation layer, HDL: hole depletion layer, EDL: electron depletion layer)

current flowing through the n-type $\mathrm{SnO}_{2}$ nanowire core, although both electron and hole currents flowed; notably, a change in the transport mode enhanced the sensing behavior.

To the total resistance induced by introduction of $\mathrm{H}_{2} \mathrm{~S}$, the contribution by the $\mathrm{SnO}_{2}$ core was higher than that by the $\mathrm{Si}$ shell. Because sensor total current comprises an $\mathrm{SnO}_{2}$ core and a Si-shell in parallel, the equivalent resistance $\mathrm{R}_{\mathrm{eq}}$ could be defined by the following equation: $1 / R_{e q}=1 / R_{n}+1 / R_{p}$, where $R_{n}$ and $R_{p}$ are the resistances of the n-type core and $p$ type shell, respectively. Because the total resistance (equivalent resistance) was smaller than $R_{n}$ and $R_{p}$, the simultaneous presence of the $\mathrm{SnO}_{2}$ core and Si-shell generated a higher sensor response.

As shown in Fig. 6, the fabricated sensor exhibited selectivity toward $\mathrm{H}_{2} \mathrm{~S}$ gas. The $\mathrm{Si}$ shell layer contributed to enhancement of the sensing activity of the sensor. The $\mathrm{Si}$ shell was covered with a thin native oxide $\left(\mathrm{SiO}_{\mathrm{x}}\right)$ layer due to the exposure of the $\mathrm{Si}$ shell to air. This resulted in a 
significant decrease in the sensing activity, because of insulating characteristics of silicon oxide. Thus, possibly $\mathrm{H}_{2} \mathrm{~S}$ gas molecules attacked and partially removed the $\mathrm{SiO}_{\mathrm{x}}$ layer. Another possibility is that $\mathrm{H}_{2} \mathrm{~S}$ decomposed, generating $\mathrm{H}_{2}$ gas species by the following reaction: $2 \mathrm{H}_{2} \mathrm{~S} \rightarrow 2 \mathrm{H}_{2}+\mathrm{S}_{2}$. This reaction has been reported to easily occur at high temperatures in the presence of metal catalysts, sulfide catalysts, and sulfur bacteria [30]. Although the sensing temperature in the present work was not high, possibly $\mathrm{SnO}_{2}$ or interstitial $\mathrm{Sn}$ played a catalytic role in the decomposition of $\mathrm{H}_{2} \mathrm{~S}$. The generated $\mathrm{H}_{2}$ might have reacted with $\mathrm{SiO}_{\mathrm{x}}$, leading to the removal of the silicon oxide layer. The other possibility is that $\mathrm{H}_{2} \mathrm{~S}$ gas molecules directly reacted with the silicon oxide layer according to the following reaction: $\mathrm{SiO}_{2}$ $+2 \mathrm{H}_{2} \mathrm{~S} \rightarrow \mathrm{SiS}_{2}+2 \mathrm{H}_{2} \mathrm{O}$. However, the Gibbs free energy for the above reaction is positive at the sensing temperature of $100{ }^{\circ} \mathrm{C}$; therefore, the direct reaction of $\mathrm{H}_{2} \mathrm{~S}$ with the native oxide would not have contributed to the removal of the oxide layer [61,62].

\section{CONCLUSIONS}

In conclusion, uncoated and Si-coated (5 nm and $10 \mathrm{~nm}$ ) $\mathrm{SnO}_{2}$ nanowires were synthesized and their gas sensing performances were investigated. At the optimal operation temperature $\left(100^{\circ} \mathrm{C}\right)$, the response of Si-coated $\mathrm{SnO}_{2}$ nanowires to $\mathrm{H}_{2} \mathrm{~S}$ was higher than that of bare $\mathrm{SnO}_{2}$ nanowires. The responses of $\mathrm{SnO}_{2}$ nanowires with $5 \mathrm{~nm}$ thick Si shells and $10 \mathrm{~nm}$-thick Si shells were highly similar. However, at a high $\mathrm{H}_{2} \mathrm{~S}$ concentration (50 ppm), the response of $\mathrm{SnO}_{2}$ nanowires with $5 \mathrm{~nm}$-thick $\mathrm{Si}$ shells was higher than that of $\mathrm{SnO}_{2}$ nanowires with $10 \mathrm{~nm}$-thick $\mathrm{Si}$ shells (1.769 versus 1.629). The removal of the native $\mathrm{SiO}_{x}$ layer by $\mathrm{H}_{2} \mathrm{~S}$ gas, creation of $\mathrm{p}-\mathrm{n}$ heterojunctions, modulation of the conduction channels of both $\mathrm{SnO}_{2}$ and $\mathrm{Si}$, and creation of imperfections in Si-coated $\mathrm{SnO}_{2}$ nanowires were the main reasons for the improved response to $\mathrm{H}_{2} \mathrm{~S}$ gas. Si-coated $\mathrm{SnO}_{2}$ nanowire sensors were tested in other gas atmospheres, and the sensors revealed good selectivity to $\mathrm{H}_{2} \mathrm{~S}$ gas compared to $\mathrm{CO}$, benzene, toluene, and $\mathrm{H}_{2}$. The present study shows that coating metal oxides with $\mathrm{Si}$ can enhance their sensing response and decrease the optimal sensing temperature.

\section{ACKNOWLEDGMENTS}

This research was supported by the Basic Science Research Program through the National Research Foundation of Korea (NRF) funded by the Ministry of Education (2016R1A6A1A03013422). This work was also supported by the NRF grant funded by the Korean government (MSIT; 2019R1A2C1006193) and this work was also supported by the research fund of Hanyang University (HY-2019).

\section{REFERENCES}

1. R. Lee, M. H. Jo, T. W. Kim, H. J. Kim, and J. C. Shin, Electron. Mater. Lett. 14, 357 (2018).

2. A. Mirzaei, S. Park, H. Kheel, G.-J. Sun, S. Lee, and C. Lee, Ceram. Int. 42, 6187 (2016).

3. J. H. Lee, Y. S. Park, M. J. Jang, S. M. Park, K. H. Lee, W. S. Choi, S. M. Choi, and Y. D. Kim, Korean, J. Met. Mater. 56, 885 (2018).

4. S. V. N. T. Kuchibhatla, A. S. Karakoti, D. Bera, and S. Seal, Prog. Mater. Sci. 52, 699 (2007).

5. J. Chen, L. N. Xu, and W. Y. Li, Adv. Mater. 17, 582 (2005).

6. M. Xu and J. Zhao, Electron. Mater. Lett. 14, 499 (2018).

7. Z. Wen, S. Ci, S. Mao, S. Cui, G. Lu, K. Yu, S. Luo, Z. He, and J. Chen, J. Power Sources 234, 100 (2013).

8. S.-J. Choi and I.-D. Kim, Electron. Mater. Lett. 14, 221 (2018).

9. X. Chen, C. K. Y. Wong, C. A. Yuan, and G. Zhang, Sens. Actuators B-Chem. 177, 178 (2013).

10. J. Liao, Z. Li, G. Wang, C. Chen, S. Lv, and M. Li, Phy. Chem. Chem. Phys. 18, 4835 (2016).

11. C. R. Field, H. J. In, N. J. Begue, and P. E. Pehrsson, Anal. Chem. 83, 4724 (2011).

12. S. Kim, J. H. Bang, M. S. Choi, W. Oum, A. Mirzaei, N. Lee, H.-C. Kwon, D. Lee, H. Jeon, S. S. Kim, and H. W. Kim, Met. Mater. Int. 25, 805 (2019).

13. H. S. Woo, C. H. Kwak, I. D. Kim, and J. H. Lee, J. Mater. Chem. A 2, 6412 (2014).

14. L. L. Wang, L. P. Kang, H. Y. Wang, Z. P. Chen, and X. J. Li, Sens. Actuators B-Chem. 229, 513 (2016).

15. G.-J.Sun, J. K. Lee, W. I. Lee, R. P. Dwivedi, C. Lee, and T. Ko, Electron. Mater. Lett. 13, 260 (2017).

16. H. W. Kim, H. G. Na, Y. J. Kwon, H. Y. Cho, and C. Lee, Sens. Actuators B-Chem. 219, 22 (2015).

17. V. Srivastava and K. Jain, Mater. Lett. 169, 28 (2016).

18. A. Mirzaei, S. G. Leonardi, and G. Neri, Ceram. Int. 42, 
15119 (2016).

19. G. Neri, A. Bonavita, G. Micali, N. Donato, F. A. Deorsola, P. Mossino, I. Amato, and B. De Benedetti, Sens. Actuators B-Chem. 117, 196 (2006).

20. S. S. Kim, H. G. Na, H. W. Kim, V. Kulish, and P. Wu, Sci. Rep. 5, 1 (2015).

21. S.-W. Choi, A. Katoch, G.-J. Sun, J.-H. Kim, S.-H. Kim, and S. S. Kim, ACS Appl. Mater. Interfaces 6, 8281 (2014).

22. S. Ozdemir and J. L. Gole, Curr. Opin. Solid State Mater. Sci. 11, 92 (2007).

23. Y. F. Zhang, Y. H. Tang, N. Wang, D. P. Yu, C. S. Lee, I. Bello, and S. T. Lee, Appl. Phys. Lett. 72, 1835 (1998).

24. W. Zhang, M. Hu, X. Liu, Y. Wei, N. Li, and Y. Qin, J. Alloy. Compd. 679, 391 (2016).

25. X. Liu, M. Hu, Y. Wang, J. Liu, and Y. Qin, J. Alloy. Compd. 685, 364 (2016).

26. H. W. Kim and S. H. Shim, J. Korean Phys. Soc. 47, 516 (2005).

27. H. W. Kim, J. W. Lee, S. H. Shim, and C. Lee, J. Korean Phys. Soc. 51, 198 (2007).

28. D. T. T. Le, D. D. Trung, N. D. Chinh, B. T. Thanh, H. S. Hong, N. Van Duy, N. D. Hoa, and N. Van Hieu, Curr. Appl. Phys. 13, 1637 (2013).

29. S. Park, S. Kim, G.-J. Sun, S. Choi, S. Lee, and C. Lee, Ceram. Int. 41, 9823 (2015).

30. S. An, J. Thermodyn. Catal. 8, 1000186 (2017).

31. S. Park, S. Park, J. Jung, T. Hong, S. Lee, H. W. Kim, and C. Lee, Ceram. Int. 40, 11051 (2014).

32. P. S. Shewale, Y. S. Yu, J.-H. Kim, C. R. Bobaded, and M. D. Uplane, J. Anal. Appl. Pyrolysis 112, 348 (2015).

33. D. L. Feucht, J. Vac. Sci. Technol. 14, 57 (1977).

34. M. N. Islam and M. O. Hakim, J. Mater. Sci. Lett. 5, 63 (1986).

35. R. G. Gordon, MRS Bull. 25, 52 (2000).

36. S. Gubbala, H. B. Russell, H. Shah, B. Deb, J. Jasinski, H. Rypkema, and M. K. Sunkara, Energy Environ. Sci. 2, 1302 (2009).

37. J.-H. Kim, H. W. Kim, and S. S. Kim, Sens. Actuators BChem. 239, 578 (2017).

38. S.-W. Choi, A. Katoch, J. Zhang, and S. S. Kim, Sens. Actuators B-Chem. 176, 585 (2013).

39. S.-W. Choi, A. Katoch, G.-J. Sun, and S. S. Kim, Sens. Actuators B-Chem. 181, 787 (2013).

40. J. Y. Park, S.-W. Choi, and S. S. Kim, J. Phys. D. Appl. Phys. 44, 205403 (2011).

41. A. Katoch, Z. U. Abideen, H. W. Kim, and S. S. Kim, $A C S$
Appl. Mater. Interfaces 8, 2486 (2016).

42. J.-H. Kim, P. Wu, H. W. Kim, and S. S. Kim, ACS Appl. Mater. Interfaces 8, 7173 (2016).

43. S.-W. Choi, A. Katoch, J.-H. Kim, and S. S. Kim, ACS Appl. Mater. Interfaces 6, 17723 (2014).

44. Y. J. Kwon, H. G. Na, S. Y. Kang, M. S. Choi, J. H. Bang, T. W. Kim, A. Mirzaei, and H. W. Kim, Sens. Actuators BChem. 239, 180 (2017).

45. J.-H. Kim, J.-H. Lee, A. Mirzaei, H. W. Kim, and S. S. Kim, Sens. Actuators B-Chem. 248, 500 (2017).

46. M. Batzill and U. Diebold, Prog. Surf. Sci. 79, 47 (2005).

47. X. Fang, J. Yan, L. Hu, H. Liu, and P. S. Lee, Adv. Funct. Mater. 22, 1613 (2012).

48. R. S. Becker, G. S. Higashi, Y. J. Chabal, and A. J. Becker, Phys. Rev. Lett. 65, 1917 (1990).

49. L. Hao, Y. Liu, W. Gao, Y. Liu, Z. Han, L. Yu, Q. Xue, and J. Zhu, J. Alloy. Compd. 682, 29 (2016).

50. X. Li, H. Zhu, K. Wang, A. Cao, J. Wei, C. Li, Y. Jia, Z. Li, X. Li, and D. Wu, Adv. Mater. 22, 2743 (2010).

51. R. M. Feenstra, J. A. Stroscio, and A. P. Fein, Surf. Sci. 181, 295 (1987)

52. P. Dwivedi, N. Chauhan, P. Vivekanandan, S. Das, D. S. Kumar, and S. Dhanekar, Sens. Actuators B-Chem. 249, 602 (2017)

53. D. Yan, S. Li, S. Liu, M. Tan, and M. Cao, J. Alloy. Compd. 735, 718 (2017).

54. W. Yan, M. Hu, D. Wang, and C. Li, Appl. Surf. Sci. 346, 216 (2015).

55. W. Yan, M. Hu, J. Liang, D. Wang, Y. Wei, W. Zhang, and Y. Qin, Mater. Res. Bull. 83, 453 (2016).

56. Y. Qin, Z. Cui, T. Zhang, and D. Liu, Sens. Actuators BChem. 258, 246 (2018).

57. A. Kobayashi, F. Grey, R. S. Williams, and M. Aono, Science 259, 1724 (1993).

58. L.-W. Wang and A. Zunger, J. Chem. Phys. 100, 2394 (1994).

59. H. Tai, X. Xu, Z. Ye, C. Liu, G. Xie, and Y. Jiang, Chem. Phys. Lett. 621, 58 (2015).

60. Y. Liu, L. Hao, W. Gao, Z. Wu, Y. Lin, G. Li, W. Guo, L. Yu, H. Zeng, J. Zhu, and W. Zhang, Sens. Actuators B-Chem. 211, 537 (2015).

61. I. Barin, Thermochemical Data of Pure Substances, 3rd ed., Wiley, New Jersey (1997).

62. R. Lee, M. H. Jo, T. W. Kim, H. J. Kim, and J. C. Shin, Electron. Mater. Lett. 14, 357 (2018). 